\title{
Flexural and Shear Behaviors of Reinforced Alkali-Activated Slag Concrete Beams
}

\author{
Kwang-Myong Lee, ${ }^{1}$ Sung Choi, ${ }^{1}$ Jinkyo F. Choo, ${ }^{2}$ Young-Cheol Choi, ${ }^{3}$ and Sung-Won Yoo ${ }^{4}$ \\ ${ }^{1}$ Department of Civil and Environmental System Engineering, Sungkyunkwan University, 2066 Seobu-ro, \\ Jangan-gu, Suwon 16419, Republic of Korea \\ ${ }^{2}$ Department of Energy Engineering, Konkuk University, 120 Neungdong-ro, Gwangjin-gu, Seoul 05029, Republic of Korea \\ ${ }^{3}$ Department of Architectural Engineering, Gachon University, 1342 Seongnamdaero, Sujeong-gu, Seongnam-si, \\ Gyeonggi-do 13120, Republic of Korea \\ ${ }^{4}$ Department of Civil and Environmental Engineering, Gachon University, 1342 Seongnamdaero, Sujeong-gu, \\ Seongnam-si, Gyeonggi-do 13120, Republic of Korea
}

Correspondence should be addressed to Sung-Won Yoo; imysw@gachon.ac.kr

Received 4 April 2017; Revised 24 May 2017; Accepted 11 June 2017; Published 20 July 2017

Academic Editor: Tung-Chai Ling

Copyright (C) 2017 Kwang-Myong Lee et al. This is an open access article distributed under the Creative Commons Attribution License, which permits unrestricted use, distribution, and reproduction in any medium, provided the original work is properly cited.

The material properties of cement-zero concrete using alkali-activators have been studied extensively as the latest response to reduce the $\mathrm{CO}_{2}$ exhaust of the cement industry. However, it is also critical to evaluate the behavior of reinforced concrete beams made of alkali-activated slag (AAS) concrete in terms of flexure and shear to promote the applicability of AAS concrete as structural material. Accordingly, nine types of beam specimens with various ratios of tensile steel and stirrup were fabricated and subject to bending and shear tests. The results show that the flexural and shear behaviors of the reinforced AAS concrete members are practically similar to those made of normal concrete and indicate the applicability of the conventional design code given that the lower density of slag is considered. In addition, a framework using the elastic modulus and stress-strain relation from earlier research is adopted to carry out nonlinear finite element analysis reflecting the material properties of AAS concrete. The numerical results exhibit good agreement with the experimental results and demonstrate the validity of the analytical model.

\section{Introduction}

The cement and concrete industries count among the primary producers of $\mathrm{CO}_{2}$ and prediction forecasts that the worldwide consumption of cement will continue to increase yearly by 2.5 to $5.8 \%$ during the second and third decades of the 21 st century [1]. As an attractive solution to prevent or at least delay the global warming caused by the emission of greenhouse gases, research was implemented worldwide to fabricate cement-zero concrete using slag powder, fly ash, and alkali-activators [2-4]. Experimental works especially reported that concrete using alkali-activated slag (AAS) instead of blast-furnace slag could develop high early strength higher than $50 \mathrm{MPa}$ even at ambient temperature and resist chemical attack by sulfates $[5,6]$.
To date, studies focused essentially on the material properties of cement-zero concrete using AAS like the strength, drying shrinkage, autogenous shrinkage, and durability. For example, Oh et al. [7] studied the autogenous shrinkage of fresh AAS mortar according to the water-to-binder ratio to assess the effect of the rapid alkaline reaction occurring at early age caused by the introduction of large amount of AAS. Collins and Sanjayan [8] compared the workability and equivalent one-day strength of AAS concrete to those of Portland cement concrete at normal curing temperature and reported discrepancies in the mechanical properties like the compressive strength, elastic modulus, flexural strength, drying shrinkage, and creep. Sofi et al. [9] considered six inorganic polymer concrete (IPC) mixes to evaluate the effects of the inclusion of coarse aggregates and granulated 
blast furnace slag. These authors carried out tests and found out that, in most cases, the engineering properties developed by the IPC mixes compared favorably to those predicted by the relevant standards for concrete mixtures. Atiş et al. [10] applied liquid sodium silicate, sodium hydroxide, and sodium carbonate (SC) at different sodium concentrations to produce AAS concrete mixes and recommended using SC as activator for slag mortar since it could achieve adequate strength and setting times and shrinkage comparable to Portland cement concrete. Using such SC activator, Melo Neto et al. [11] examined the relationship between the hydration, unrestrained drying, and autogenous shrinkage of AAS mortar specimens. These authors reported the critical influence of the amount of activator on the drying and autogenous shrinkages, and the significant contribution of the autogenous shrinkage on the total shrinkage. Besides, Puertas et al. [12] analyzed the behavior of AAS mortars after carbonation. The results indicated that AAS mortars were more intensely and deeply carbonated than Portland cement mortars.

These previous studies gave insight on the adequate mix to achieve AAS mortars exhibiting material properties comparable to Portland cement mortars. However, research shall also be implemented on the elastic modulus, stress-strain relations, and behavior of structural members to exploit AAS concrete as structural material. Recently, Lee and Seo [13] and Choi et al. [14] evaluated experimentally the flexural and shear behaviors of AAS concrete beams but without attempting to model these behaviors at once and analytically.

Accordingly, this study investigates experimentally and analytically the structural behavior of AAS concrete members and intends to verify the applicability of existing cementbased concrete design code to AAS concrete. To that goal, the behavior of reinforced concrete beams made of AAS concrete is evaluated experimentally in terms of both flexure and shear. In addition, the elastic modulus and stress-strain relation of AAS concrete for 50-MPa precast members obtained experimentally are used to perform the finite element analysis of the flexural members and shear members and the numerical results are compared to the experimental data.

\section{Test Setup}

2.1. Materials. Ground granulated blast furnace slag (GGBFS) with density of $2.90 \mathrm{~g} / \mathrm{cm}^{3}$, fineness of $4,365 \mathrm{~cm}^{2} / \mathrm{g}$, and basicity of 1.78 is used as binder. River sand with density of $2.58 \mathrm{~g} / \mathrm{cm}^{3}$ and fineness modulus of 2.92 is used as fine aggregate. Crushed stone with density of $2.62 \mathrm{~g} / \mathrm{cm}^{3}$ and maximum size of $19 \mathrm{~mm}$ is adopted as coarse aggregate. Two types of alkali-activators that are sodium hydroxide (98\% purity) and industrial water glass with $\mathrm{SiO}_{2}=28.8 \%$ and $\mathrm{Na}_{2} \mathrm{O}=9.3 \%$ are used to activate the GGBFS. These two products are added to realize $\mathrm{Na}_{2} \mathrm{O}=6.0 \%$ and alkali modulus $\mathrm{Ms}\left(=\mathrm{SiO}_{2} / \mathrm{Na}_{2} \mathrm{O}\right)$ of 1.0 with respect to the mass of slag. Moreover, polycarbonate superplasticizer is adopted to secure the fluidity of AAS concrete.

2.2. Characteristics of Concrete and Reinforcement. Table 1 arranges the mix proportions of AAS concrete purposed for

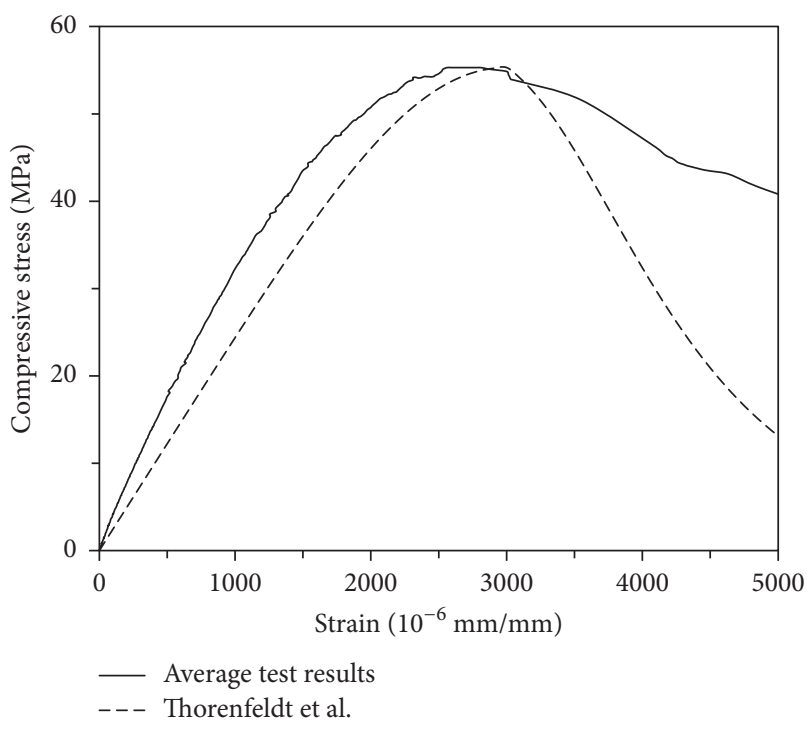

FIGURE 1: Stress-strain relationship of considered AAS concrete in compression.

50-MPa precast products and used for the fabrication of the beam specimens. In Table $1, W / B$ stands for water-to-binder ratio, $S / a$ for fine-to-aggregate ratio, and $W$ for water. Table 2 lists the properties of fresh AAS concrete together with the elastic modulus and strength of AAS concrete at 28 days. The compressive strength at 3 days is $32 \mathrm{MPa}$ and the compressive strength and elastic modulus at 28 days are $55.3 \mathrm{MPa}$ and $31.5 \mathrm{GPa}$, respectively.

Figure 1 plots the stress-strain relationship of AAS concrete in compression. The value of 0.003 obtained for the ultimate compressive strain of AAS concrete appears to be similar to that of ordinary Portland cement (OPC). The test results are also compared with the values given by the following analytical model suggested by Thorenfeldt et al. [16] for OPC.

$$
f_{\mathrm{c}}=f_{\mathrm{cm}} \times \frac{\varepsilon_{\mathrm{c}}}{\varepsilon_{\mathrm{cm}}} \times \frac{n}{n-1+\left(\varepsilon_{\mathrm{c}} / \varepsilon_{\mathrm{cm}}\right)^{n k}},
$$

where $f_{\mathrm{c}}$ and $\varepsilon_{\mathrm{c}}$ are strength and strain of concrete, respectively; $f_{\mathrm{cm}}$ is peak stress $(\mathrm{MPa}) ; \varepsilon_{\mathrm{cm}}$ is strain at peak stress; and $n=0.8+\left(f_{\mathrm{cm}} / 17\right)$ with $k=0.67+\left(f_{\mathrm{cm}} / 62\right)$ if $\varepsilon_{\mathrm{c}}>\varepsilon_{\mathrm{cm}}$ and $k=1$ if $\varepsilon_{\mathrm{c}} \leq \varepsilon_{\mathrm{cm}}$.

Figure 1 shows good agreement of the stress-strain relationship between the test results and the model of Thorenfeldt et al. [16] up to the ultimate strain. However, AAS concrete exhibits more ductile behavior than the analytical model beyond the ultimate strain.

Besides, the tensile reinforcement and stirrup are, respectively, made of steel SD500 and SD400 of which average yield strengths derived from direct tensile test are $499.6 \mathrm{MPa}$ and 419.2 MPa $[13,14]$. Tests were performed on $\phi 100 \times 200 \mathrm{~mm}$ cylinders fabricated to examine the stress-strain relation and derive the elastic modulus of AAS concrete.

2.3. Test Variables. For the flexural test, three levels of reinforcement ratio (balanced steel ratio of 76,58 , and $43 \%$ ) were 
TABLE 1: Mix proportions of AAS concrete.

\begin{tabular}{lcccccccc}
\hline$W / B(\%)$ & \multirow{2}{*}{$S / a(\%)$} & $W$ & GGBFS & Fine aggregate & Coarse aggregate & Water glass & NaOH & Superplasticizer \\
\hline 45 & 50 & 165 & 367 & 855 & 869 & 73 & 19 & 3.67 \\
\hline
\end{tabular}

TABLE 2: Properties of AAS concrete.

\begin{tabular}{lcccc}
\hline \multicolumn{2}{c}{ Fresh concrete } & \multicolumn{2}{c}{ Hardened concrete (28 days) } \\
Slump $(\mathrm{mm})$ & Air content $(\%)$ & Compressive strength $(\mathrm{MPa})$ & Elastic modulus (GPa) & Splitting tensile strength (MPa) \\
\hline 165 & 3.1 & 55.3 & 31.5 & 3.9 \\
\hline
\end{tabular}

selected as test variables to examine the flexural behavior of the AAS concrete specimens for 50-MPa precast products. Therefore, 3 types of beam specimens were fabricated. In the specimens, the stirrups (D10) are arranged densely with spacing of $70 \mathrm{~mm}$ to prevent shear failure. Moreover, three levels of tensile reinforcement ratio (balanced steel ratio of $76,58$, and $43 \%)$ and 2 levels of stirrup spacing $((1 / 2) d$, no stirrup) were chosen as test variables of the beam specimens for the shear test. Here, six types of beam specimens were fabricated for the shear tests.

2.4. Details of Test Specimens. Table 3 lists the beam specimens with their designation and corresponding test variables for the examination of the flexural and shear behaviors. Figure 2 shows the reinforcement details and dimensions of the beam specimens. Table 3 gives the detailed dimensions of the specimens. Figure 2(b) illustrates the layout of the sensors for the measurement of the steel and concrete strains and the center deflection during the loading test. Figure 3 pictures a completed beam specimen installed for loading test.

\section{Test Results and Discussion}

3.1. Flexural Behavior of AAS Concrete Members. Table 4 lists the crack load, steel yield load, and ultimate load measured in the AAS concrete members during the bending test. All the specimens failed by flexure and the load bearing capacity increased with larger tensile steel ratio. The ratio of the ultimate load to the steel yield load ranges between 1.15 and 1.41. All the specimens exhibit similar crack load because the members were fabricated using the same AAS concrete.

Figure 4 plots the load-deflection curves of the flexural members. During the increase of the load, all the specimens develop deflection quasi-proportional to the load. Then, the slope of the curves experiences steep variation after the yielding of the tensile steel. The linear part of the curves especially becomes longer with higher tensile steel ratio. Finally, brittle failure occurs after the ultimate load with steep loss of the load. This indicates that the behavior of the AAS concrete beams depends sensitively on the steel ratio similarly to the beams made of normal concrete with OPC.

Figure 5(a) plots the load-strain curves of the tensile steel in the flexural members. The strain remains minimal under loading smaller than the crack load and increases linearly with larger load beyond the crack load. Moreover, the strain tends to enlarge significantly after yielding of the tensile steel. Figure 5(b) plots the load-compressive strain curves of concrete in the flexural members. The strain $\varepsilon_{0}$ at maximum stress ranges between 0.00250 and 0.00285 , and the ultimate strain ranges between 0.00250 and 0.00290 . The ultimate strain is relatively smaller than the theoretical value of 0.0038 but the peak strain $\varepsilon_{0}$ is comparable to that of the experimental stress-strain curve.

Figure 6 compares the ultimate moments of the flexural members to those provided by the following equation. This equation assumes the yielding of steel.

$$
M_{\mathrm{u}}=0.9 d \times A_{\mathrm{s}} \times f_{\mathrm{y}},
$$

where $d$ is effective depth of cross section; $A_{\mathrm{s}}$ is nominal area of reinforced bar; and $f_{\mathrm{y}}$ is yield stress.

Figure 6 shows good agreement between the experimental and computed ultimate moments with the experimental values larger by $3 \%$ to $9 \%$ than the predictions. This verifies the similar flexural behavior developed by the AAS concrete members and the OPC members.

3.2. Shear Behavior of AAS Concrete Members. Compared to a previous paper presented by the authors of [14], three additional members were fabricated and tested to complement erroneous data. Table 5 arranges the flexural crack and shear crack loads, the yield loads of the tensile steel and stirrup, and the ultimate loads obtained from the shear failure tests conducted at 28 days on the fabricated specimens. As shown in Figure 7, shear failure occurred in all the members except specimen S19-0.5d. The distinction between the shear failure and the flexural failure was done considering comprehensively the yielding of the stirrups, the eventual reaching of the ultimate strain by the flexural compressive strain of concrete, and the size of the shear strain of concrete.

The loads generating flexural cracking were similar in the six test members, which is attributable to the use of concrete with the same compressive strength in all the specimens. Besides, the members reinforced with stirrups experienced shear cracking at slightly larger load than the members without stirrup. Moreover, the shear crack load appears to be larger with higher tensile steel ratio. This can be explained by the Dowel action of the tensile steel. In other words, the Dowel action of the tensile steel delays the initiation of shear cracking as much as the tensile steel ratio is large. For the members with stirrups, the yield loads of the tensile steel become larger with higher tensile steel ratio and the ratio of 
TABLE 3: Designation of beam specimen type and corresponding test variables.

\begin{tabular}{|c|c|c|c|c|}
\hline Designation & Tensile steel $\left(A_{\mathrm{s}}\right)$ & Compression steel $\left(A_{s}^{\prime}\right)$ & D10 stirrup spacing $(\mathrm{mm})$ & Tensile steel ratio \\
\hline \multicolumn{5}{|l|}{ Flexure } \\
\hline F25 & $3-\mathrm{D} 25$ & & & 0.0304 \\
\hline $\mathrm{F} 22$ & 3-D22 & & 70 & 0.0232 \\
\hline F19 & 3-D19 & & & 0.0172 \\
\hline \multicolumn{5}{|l|}{ Shear } \\
\hline S25-0.5d & $3-\mathrm{D} 25$ & 2-D16 & & 0.0304 \\
\hline S22-0.5d & $3-\mathrm{D} 22$ & & 125 & 0.0232 \\
\hline S19-0.5d & 3-D19 & & & 0.0172 \\
\hline S25-0 & $3-\mathrm{D} 25$ & & & 0.0304 \\
\hline $\mathrm{S} 22-0$ & $3-\mathrm{D} 22$ & & 0 & 0.0232 \\
\hline S19-0 & 3-D19 & & & 0.0172 \\
\hline
\end{tabular}

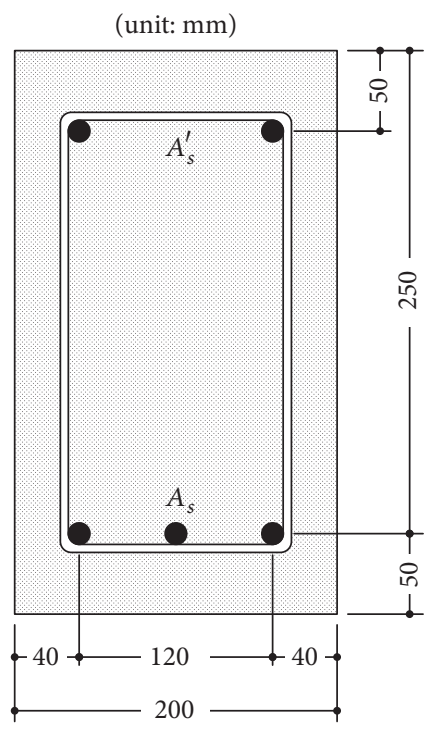

(a) Details of reinforcement

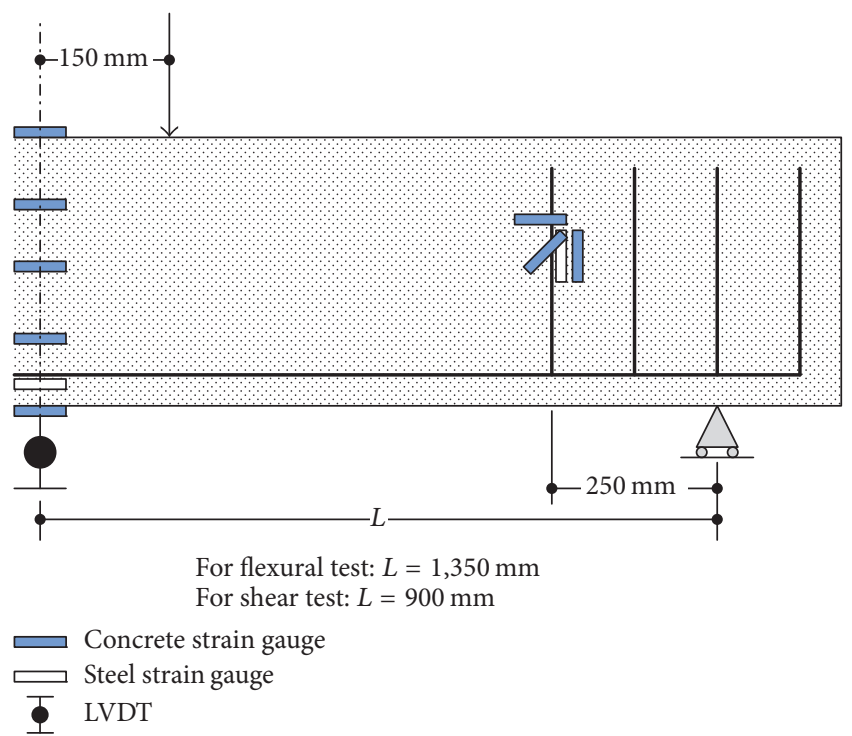

(b) Dimensions of specimens and sensor layout

FIGURE 2: Cross-sectional details and sensor layout of AAS concrete beam specimens.

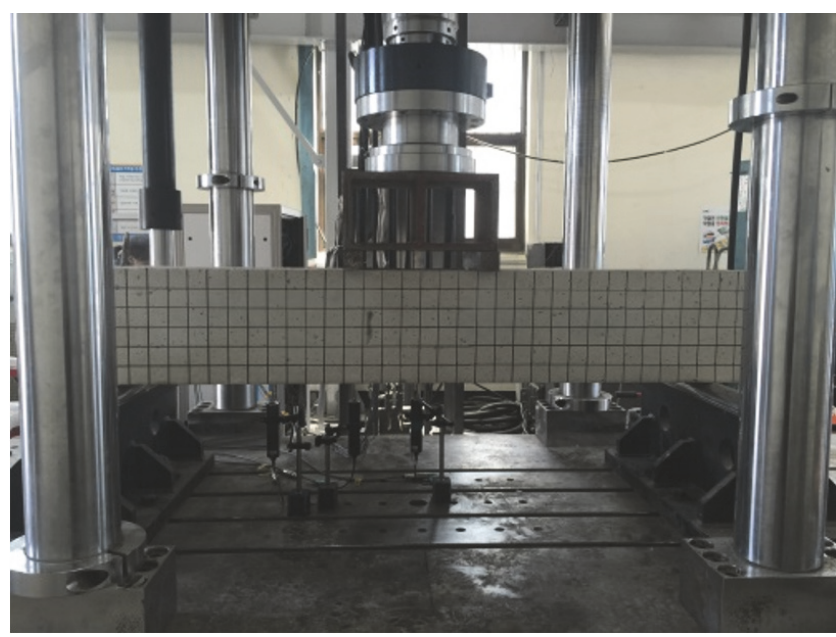

FIgURE 3: Setup for flexural test of AAS concrete beam specimen. the ultimate load to the yield load of the tensile steel ranges between 1.09 and 1.58 .

Figure 8 plots the load-deflection curves obtained from the shear test of the beam specimens. All the curves are quasilinear before early cracking and, beyond that point, increase nonlinearly until the ultimate state. It appears that the tensile steel ratio has significant influence on the structural behavior of the beams. The shear behavior of the AAS concrete beam specimens is similar to that of the beams made of normal concrete. The specimens without stirrup especially failed as soon as the ultimate load was attained. Note that the specimens with stirrups experienced brittle failure practically without ductile behavior due to the minimum arrangement of stirrups adopted in this study. This means that, when shear failure occurs in absence of stirrup (specimens S25-0 and S220 ), the member shows common recovery of its resistance to shear owing to the Dowel action even after the first strength degradation. However, specimen S19-0 experienced flexural 
TABLE 4: Crack, yield and ultimate loads and corresponding center displacement of flexural test specimens.

\begin{tabular}{|c|c|c|c|c|c|c|c|c|}
\hline \multirow{2}{*}{ Member } & \multirow{2}{*}{ Crack load (kN) } & \multicolumn{2}{|r|}{ Yield } & \multicolumn{2}{|c|}{ Ultimate } & \multicolumn{2}{|c|}{ Ultimate/Yield } & \multirow{2}{*}{ Failure mode } \\
\hline & & Load $(\mathrm{kN})$ & Deflection $(\mathrm{mm})$ & Load $(\mathrm{kN})$ & Deflection (mm) & Load ratio & Deflection ratio & \\
\hline F25 & 20.6 & 272.5 & 13.8 & 313.4 & 18.1 & 1.15 & 1.31 & Flexure \\
\hline $\mathrm{F} 22$ & 24.4 & 171.9 & 10.8 & 242.3 & 24.5 & 1.41 & 2.27 & Flexure \\
\hline F19 & 22.4 & 155.6 & 10.9 & 188.4 & 23.3 & 1.21 & 2.14 & Flexure \\
\hline
\end{tabular}

TABLE 5: Crack, yield, and ultimate loads of shear test specimens.

\begin{tabular}{|c|c|c|c|c|c|c|}
\hline \multirow{2}{*}{ Member } & \multicolumn{2}{|c|}{ Crack load $(\mathrm{kN})$} & \multirow{2}{*}{ Yield load of tensile steel, $a(\mathrm{kN})$} & \multirow{2}{*}{ Ultimate load, $b(\mathrm{kN})$} & \multirow{2}{*}{$b / a$} & \multirow{2}{*}{ Failure mode } \\
\hline & Flexure & Shear & & & & \\
\hline S25-0.5d & 34.6 & 163.2 & 228.5 & 249.6 & 1.09 & Shear \\
\hline S22-0.5d & 30.9 & 152.2 & 144.6 & 228.3 & 1.58 & Shear \\
\hline S19-0.5d & 25.1 & 134.0 & 127.5 & 176.5 & 1.38 & Flexure \\
\hline S25-0 & 30.7 & 125.9 & - & 85.3 & - & Shear \\
\hline S22-0 & 28.2 & 118.6 & - & 100.8 & - & Shear \\
\hline S19-0 & 32.9 & 112.9 & 94.3 & 111.2 & 1.18 & Flexural shear \\
\hline
\end{tabular}

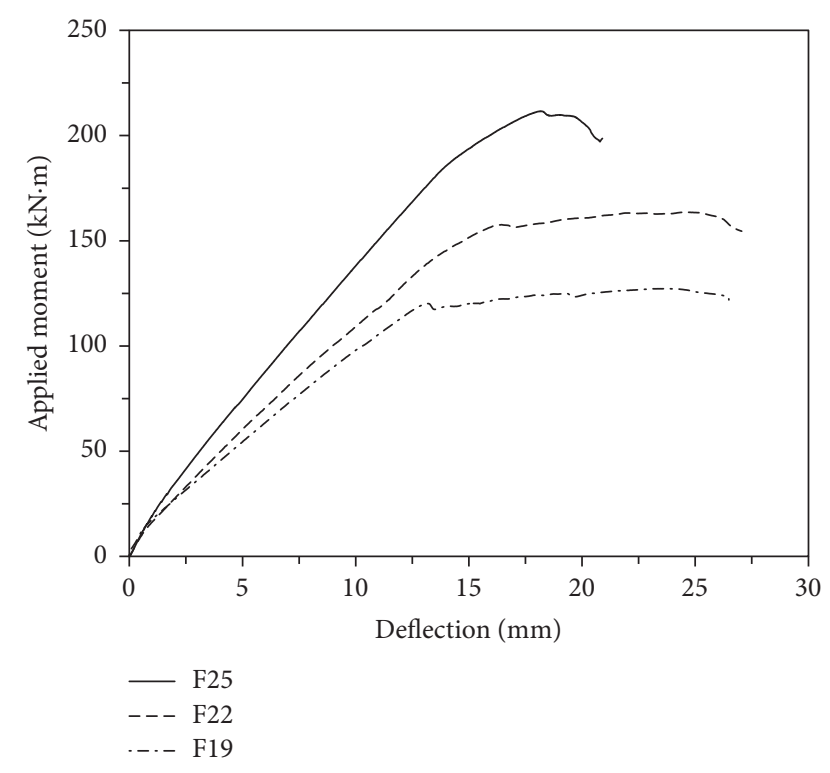

Figure 4: Comparison of load-deflection curves of flexural test specimens.

shear failure instead of pure shear failure due to the Dowel action of the tensile reinforcement. This explains the absence of strength recovery after the loss of early strength.

Figure 9 draws the load-strain curves of the tensile steel measured in the shear test specimens. In view of the results presented in Table 5 and Figure 9, specimens S250, S25-0.5d, and S22-0 experienced pure shear failure before yielding of the tensile reinforcement. Specimen S25-0.5d, as the one having the largest arrangement of tensile steel, exhibits small increase of the strain in the tensile steel because the specimen reached the ultimate load following the occurrence of shear failure immediately after yielding of the tensile reinforcement. Specimens S25-0 and S22-0 without stirrup and small arrangement of tensile steel experienced sudden failure before yielding of the tensile steel once the load exceeded the shear strength due to the absence of stirrups.

On the other hand, the other specimens saw their tensile reinforcement deform at shear failure and without increase of the load because shear failure occurred after yielding of the tensile reinforcement. Specimens S22-0.5d and S19-0.5d with relatively small arrangement of tensile reinforcement experienced large deformation after yielding of the tensile steel and finally failed, respectively, through flexure/shear or flexure. Despite the absence of stirrups, specimen S19-0 failed through flexure/shear due to the small amount of tensile steel and developed relatively larger strain than the other specimens without stirrup.

Figure 10 plots the load with respect to the flexural compressive strain of concrete measured in the shear test specimens. Specimen S25-0.5d with large amount of tensile steel failed before concrete reached its ultimate strain due to the sudden occurrence of shear failure. Specimens S22$0.5 \mathrm{~d}$ and S19-0.5d reinforced by stirrups and small amount of tensile steel were the only ones to develop relatively large concrete strain up to 0.0035 because of the following reasons. Specimen S22-0.5d experienced flexural failure at first due to its small amount of tensile steel and finally failed through shear due to its small amount of stirrup. Specimen S19$0.5 \mathrm{~d}$ experienced flexural failure without shear failure due to its smaller amount of tensile steel. In addition, among the members without stirrup, specimens S25-0 and S22-0 developed small concrete strain due to the sudden occurrence of shear failure.

Figure 11(a) plots the load with respect to the shear strain measured in the stirrups. It appears that the stirrup yielded only in specimen S25-0.5d and not in the other two specimens. This is in agreement with the failure modes listed in Table 5, which indicated pure shear failure in specimen S25-0.5, flexure-shear failure in specimen S22-0.5d, and flexural failure in specimen S19-0.5d. Besides, specimens S22-0.5d and S19-0.5d that did not experience yielding of their stirrup recorded values of 0.00263 and 0.00262 for the 


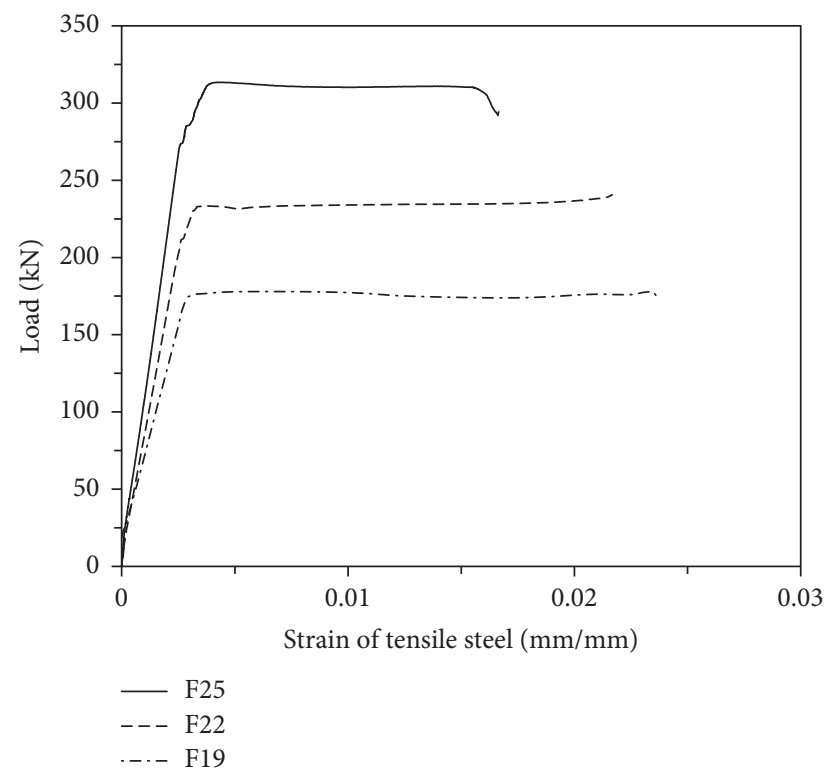

(a) Load-strain curves of tensile steel

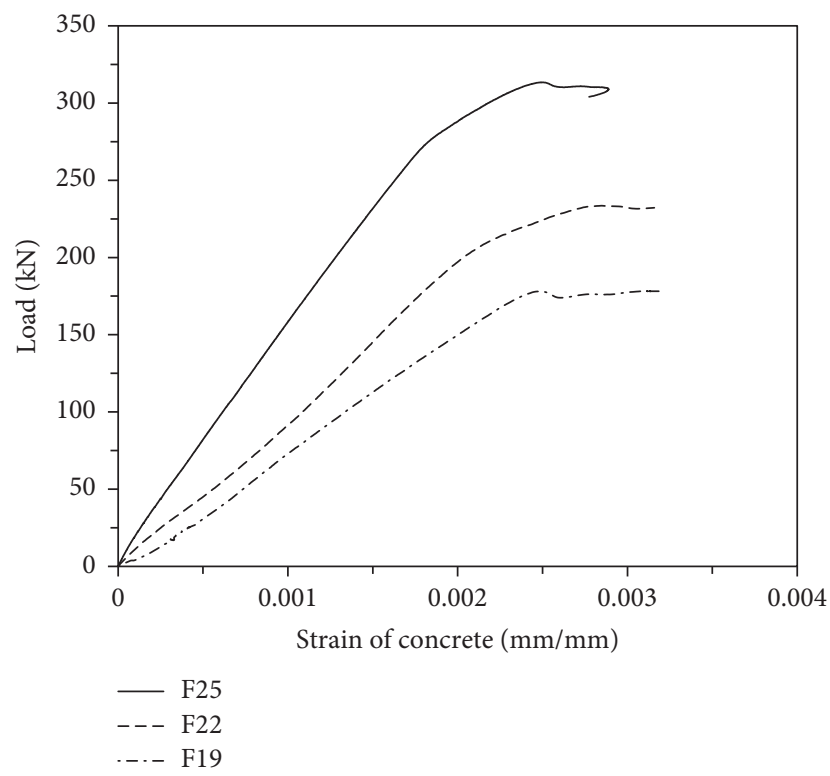

(b) Load-strain curves of concrete

FIGURE 5: Load-strain curves of flexural test specimens according to steel ratio.

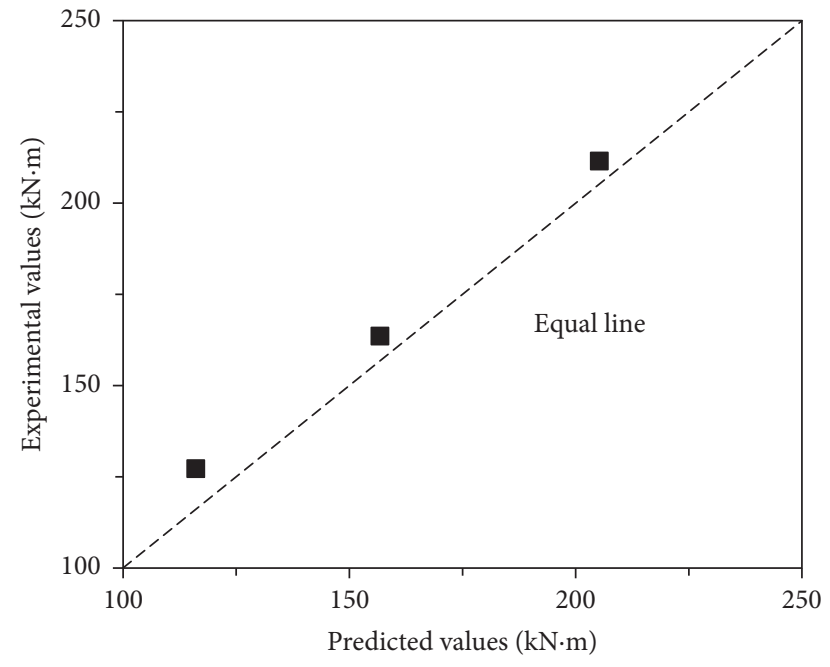

FIGURE 6: Comparison of experimental and predicted ultimate moments.

maximum strain of the stirrup, respectively. Accordingly, the stress in the stirrup based upon the uniaxial stress-strain relationship can be estimated to be $419 \mathrm{MPa}$ for S25-0.5d, $367 \mathrm{MPa}$ for S22-0.5d, and $366 \mathrm{MPa}$ for S19-0.5d.

Figure 11(b) plots the load with respect to the principal strain measured in concrete. The members underwent shear cracking at shear strain of 0.000112 (specimen S19-0), 0.000113 (specimen S22-0), and 0.000121 (specimen S25-0). The values of the concrete principal strain were calculated by converting the strain measured by the strain gage rosette (Figure 2(b)) attached on the right-hand side of the critical section.

ACI 318-08 [17] proposes the following formulae for the calculation of the maximum shear stress $v_{\mathrm{cr}}$ of concrete.
Simplified Formula

$$
v_{\mathrm{cr}}=0.16 \sqrt{f_{\mathrm{ck}}}
$$

Elaborated Formula

$$
v_{\mathrm{cr}}=0.16 \sqrt{f_{\mathrm{ck}}}+17.6 \frac{\rho V d}{M} \leq 0.29 \sqrt{f_{\mathrm{ck}}},
$$

where $f_{\text {ck }}$ is compressive strength of concrete; $\rho$ is tensile steel ratio; $V$ is shear force at the critical section; $M$ is bending moment at the critical section; and $d$ is effective depth.

If the compressive strength, steel ratio, shear force, and bending moment are substituted in (3), $v_{\mathrm{cr}}=1.19 \mathrm{MPa}$, and $v_{\text {cr }}$ takes values of 1.31 MPa (S19-0), 1.37 MPa (S22-0), and $1.39 \mathrm{MPa}(\mathrm{S} 25-0)$ when (4) is used.

Assuming the common value of 0.17 for Poisson's ratio $\nu$, the shear stress is calculated by multiplying the shear elastic modulus $G=E_{\mathrm{c}} /[2(1+v)]=14.06 \mathrm{GPa}$ by the shear strain measured in the tests, where the experimental elastic modulus $E_{\mathrm{c}}=32.91 \mathrm{GPa}$ from Table 2. The corresponding shear stress becomes $1.58 \mathrm{MPa}(\mathrm{S} 19-0), 1.59 \mathrm{MPa}$ (S22-0), and $1.70 \mathrm{MPa}(\mathrm{S} 25-0)$. This shows that the principal stress obtained experimentally is slightly larger than that predicted by the design formulae in (3) and (4).

\subsection{Comparison of Experimental Shear Strength and Design} Values. Table 6 compares the shear strengths obtained from the test with those suggested by the design code. In Table 6, "Test" indicates the values based upon the loads measured in the test and "Analysis" designates the values computed from the strain measured in the test. Recalling that specimen S190.5d failed through flexure, S19-0.5d and S19-0 are discarded because the comparison of the shear strength is meaningless 


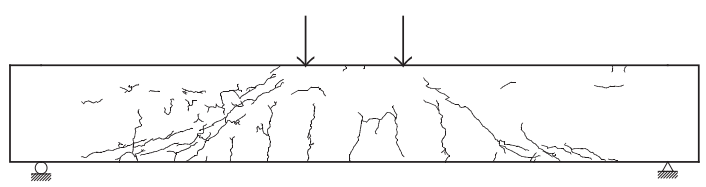

(a)

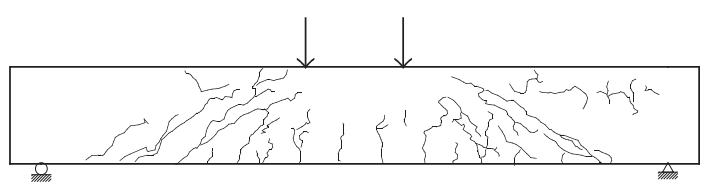

(b)

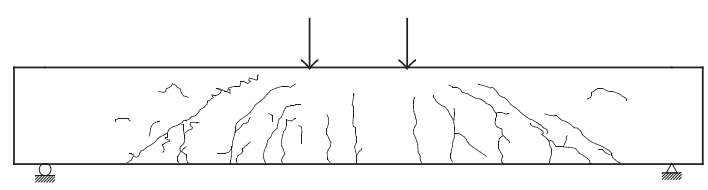

(c)

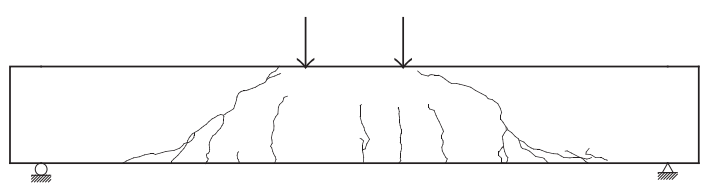

(d)

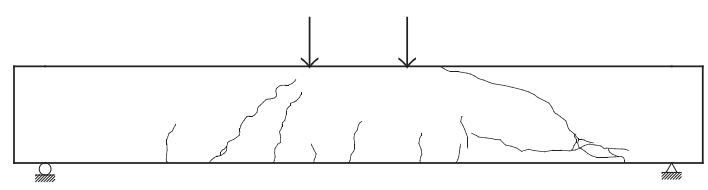

(e)

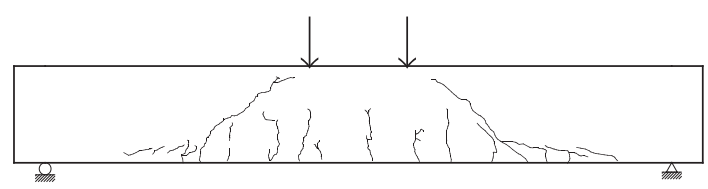

(f)

Figure 7: Crack pattern of shear test specimens (a) S25-0.5d, (b) S22-0.5d, (c) S19-0.5d, (d) S25-0, (e) S22-0, and (f) S19-0.

TABLE 6: Comparison of shear strengths from test and design code.

\begin{tabular}{|c|c|c|c|c|}
\hline Shear strength & S25-0.5d & S25-0 & S22-0.5d & S22-0 \\
\hline \multicolumn{5}{|l|}{ Test $(\mathrm{kN})$} \\
\hline$V_{\mathrm{c}}$ & 85.3 & 85.3 & 100.8 & 100.8 \\
\hline$V_{\mathrm{s}}$ & 164.3 & - & 127.5 & - \\
\hline$V_{\mathrm{u}}=V_{\mathrm{c}}+V_{\mathrm{s}}($ incl. self-weight $)$ & 251.0 & 86.7 & 229.6 & 102.2 \\
\hline \multicolumn{5}{|l|}{ Design Code $(\mathrm{kN})$} \\
\hline$V_{\mathrm{c}}$ & 86.9 & 86.9 & 80.2 & 80.2 \\
\hline$V_{\mathrm{s}}$ & 114.1 & - & 114.1 & - \\
\hline$V_{\mathrm{n}}=V_{\mathrm{c}}+V_{\mathrm{s}}$ & 201.0 & 86.9 & 194.3 & 80.2 \\
\hline $\operatorname{Test}\left(V_{\mathrm{u}}\right) / \operatorname{Code}\left(V_{\mathrm{n}}\right)$ & 1.25 & 1.00 & 1.18 & 1.27 \\
\hline \multicolumn{5}{|l|}{ Analysis $(\mathrm{kN})$} \\
\hline$V_{\mathrm{c}}$ & 85.0 & 85.0 & 79.5 & 79.5 \\
\hline$V_{\mathrm{s}}$ & 119.5 & - & 104.7 & - \\
\hline$V_{\mathrm{n}}=V_{\mathrm{c}}+V_{\mathrm{s}}($ incl. self-weight $)$ & 205.9 & 86.4 & 185.6 & 80.9 \\
\hline $\operatorname{Test}\left(V_{\mathrm{u}}\right) / \operatorname{Analysis}\left(V_{\mathrm{n}}\right)$ & 1.22 & 1.00 & 1.24 & 1.26 \\
\hline
\end{tabular}




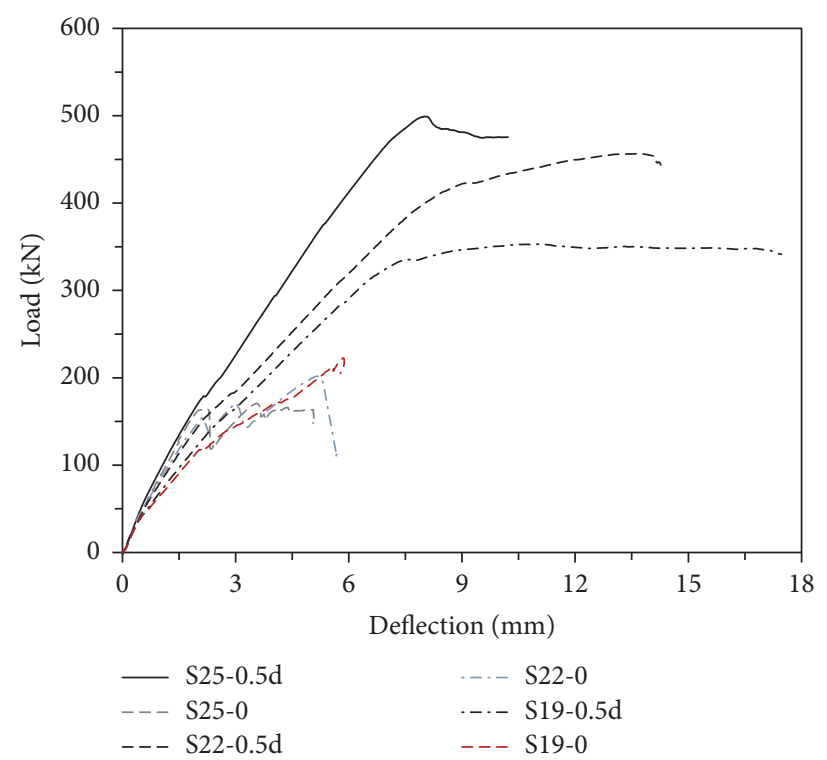

FIgURE 8: Load-deflection curves of shear test specimens.

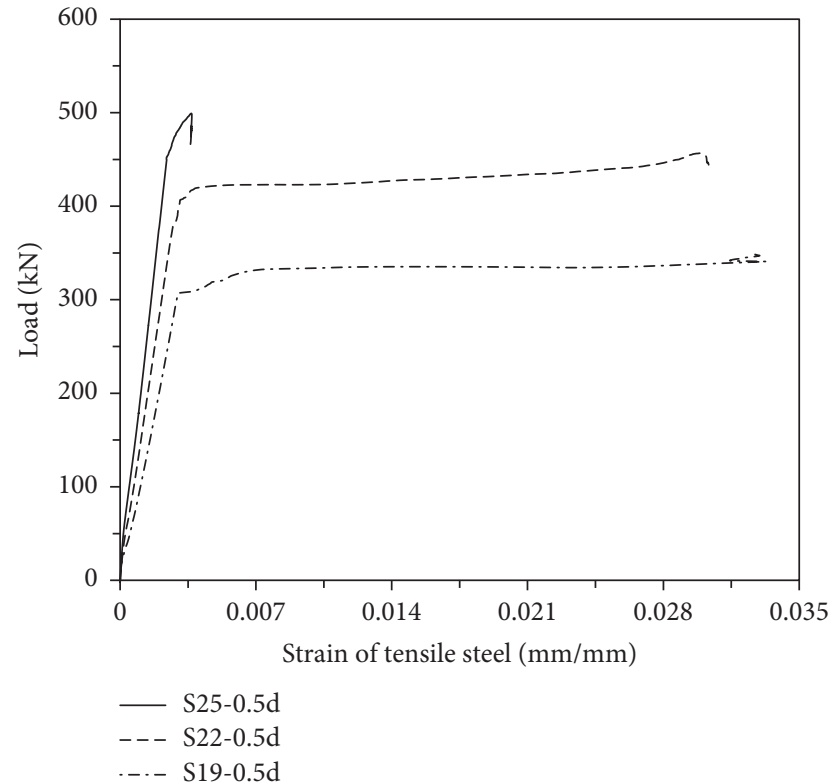

(a) With stirrups

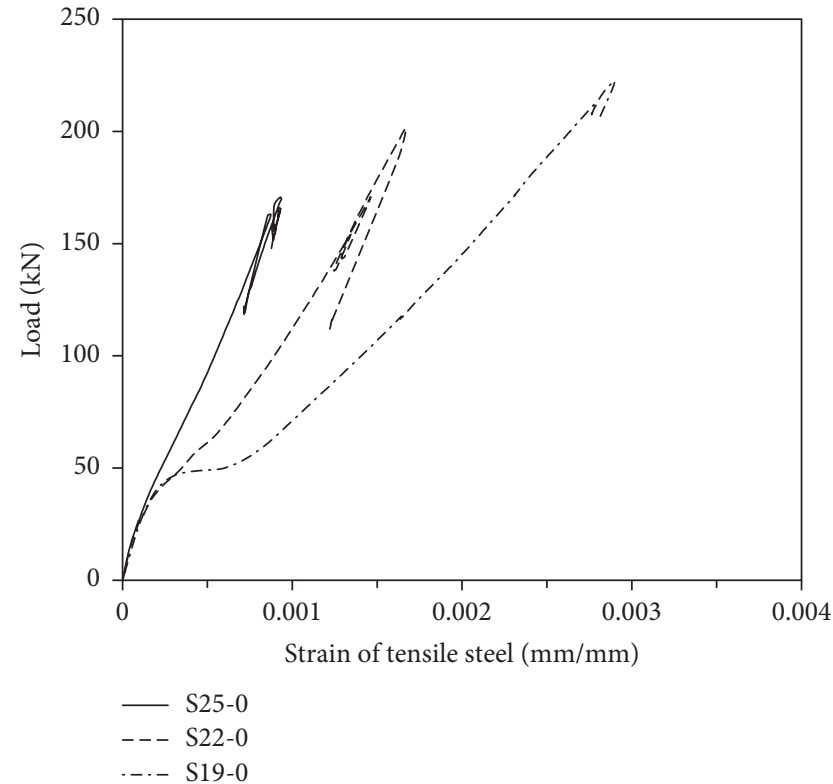

(b) Without stirrup

FIGURE 9: Load versus strain of tensile steel in shear test specimens.

for these members. In addition, the experimental shear force corresponds to the sum of the shear force obtained in the test and the self-weight $(1.35 \mathrm{kN}=25 \times 0.3 \times 0.2 \times 1.8 / 2)$; the shear strength $V_{\mathrm{c}}$ supported by concrete in the test is half of the ultimate load of the specimens without stirrup (S25-0, S22-0, S19-0); the shear strength $V_{c}$ provided by the design code is the result of the application of (2); and the shear strength sustained by the stirrups is calculated by applying $V_{\mathrm{s}}=A_{\mathrm{v}} f_{\mathrm{y}} d / s$, where $s$ is the stirrup spacing. The values of $V_{\mathrm{c}}$ in "Analysis" are computed as the product of the principal stress obtained in Figure 11(b) of Section 3.2 by the crosssectional area of the specimen. The values of $V_{s}$ in "Analysis" are calculated as the product of the strain in the stirrup obtained in Figure 11(a) of Section 3.2 by the cross-sectional area of the reinforcement.

The ratio of the experimental value to the value predicted by the design code $\left(\operatorname{Test}\left(V_{\mathrm{u}}\right) / \operatorname{Code}\left(V_{\mathrm{n}}\right)\right)$ ranges between 1.00 and 1.27 and that of the experimental value to the analytic value calculated from the experimental strain $\left(\operatorname{Test}\left(V_{\mathrm{u}}\right) / \operatorname{Analysis}\left(V_{\mathrm{n}}\right)\right)$ ranges between 1.00 and 1.26, which 


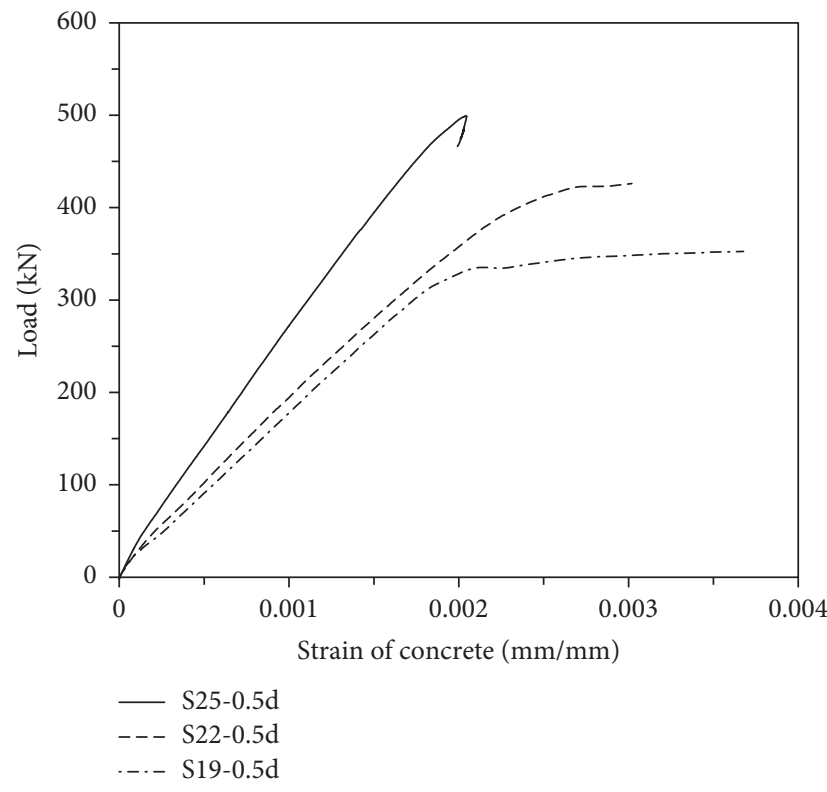

(a) With stirrups

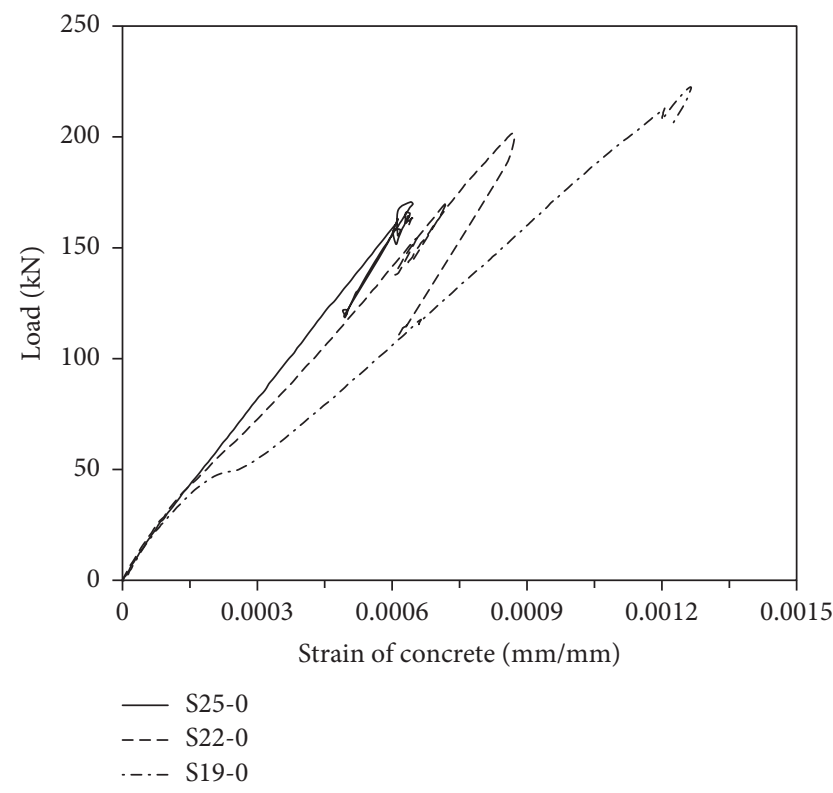

(b) Without stirrup

Figure 10: Load versus flexural compressive strain of concrete in shear test specimens.

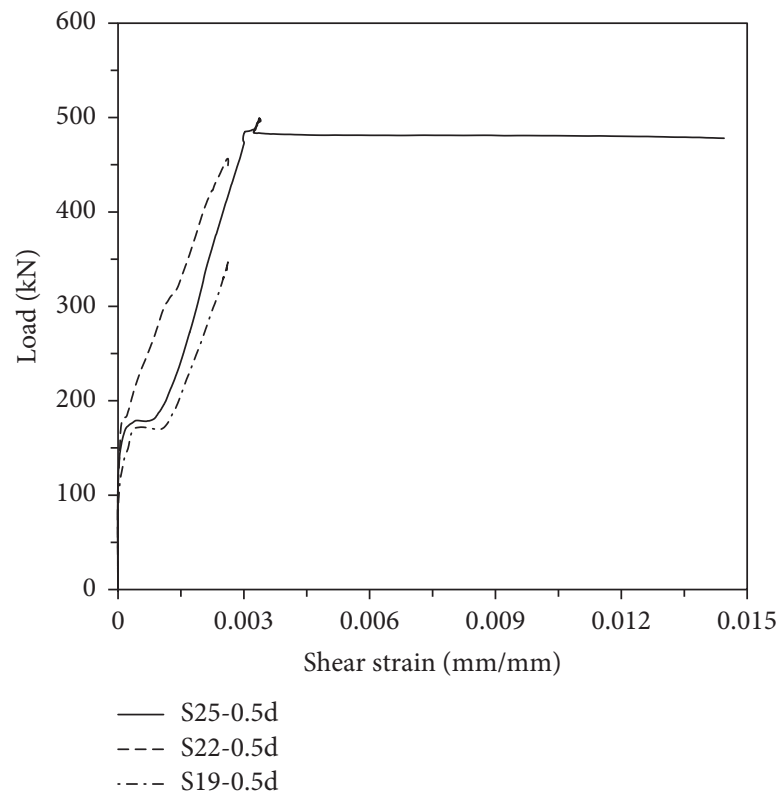

(a) Stirrups

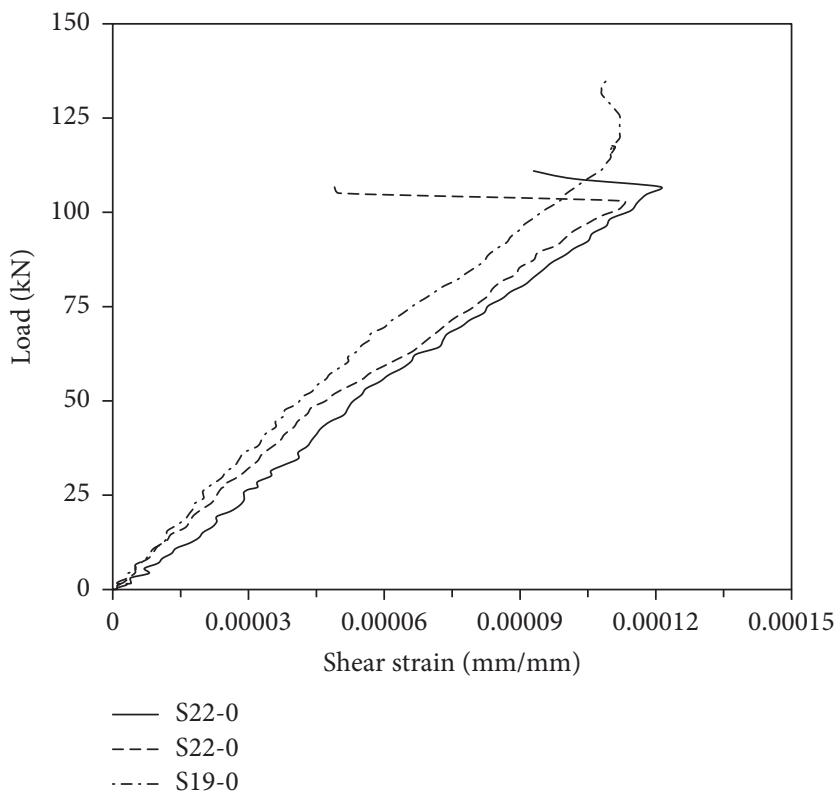

(b) Concrete

FIGURE 11: Load versus shear strain in shear test specimens.

indicate that the analysis provides values larger by maximum $26 \%$ and the similarity between the predictions of the design and the analysis.

\section{Finite Element Analysis}

4.1. Method of Analysis. The numerical analysis was carried out using the nonlinear finite element program, RCAHEST, developed by Kim et al. [15]. The analysis models consist of a compression, tension stiffening, and shear transfer model for concrete and a model for embedded reinforcing steel. The concrete-reinforcement bond interaction is considered in both the tension stiffening model for concrete and the model for reinforcement. An earlier study [18] demonstrated that the above-mentioned analysis model agreed reasonably with the experimental data. 


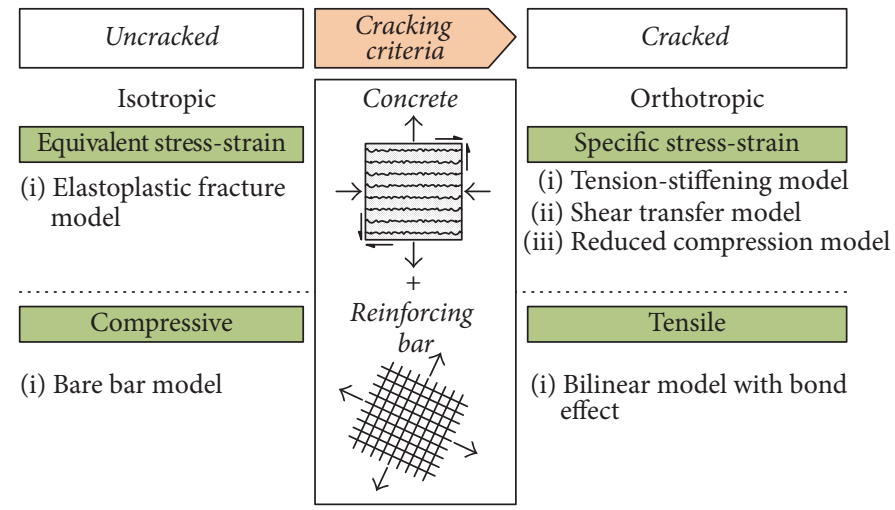

FIGURE 12: Outline of analysis model for reinforced high-strength concrete [15].

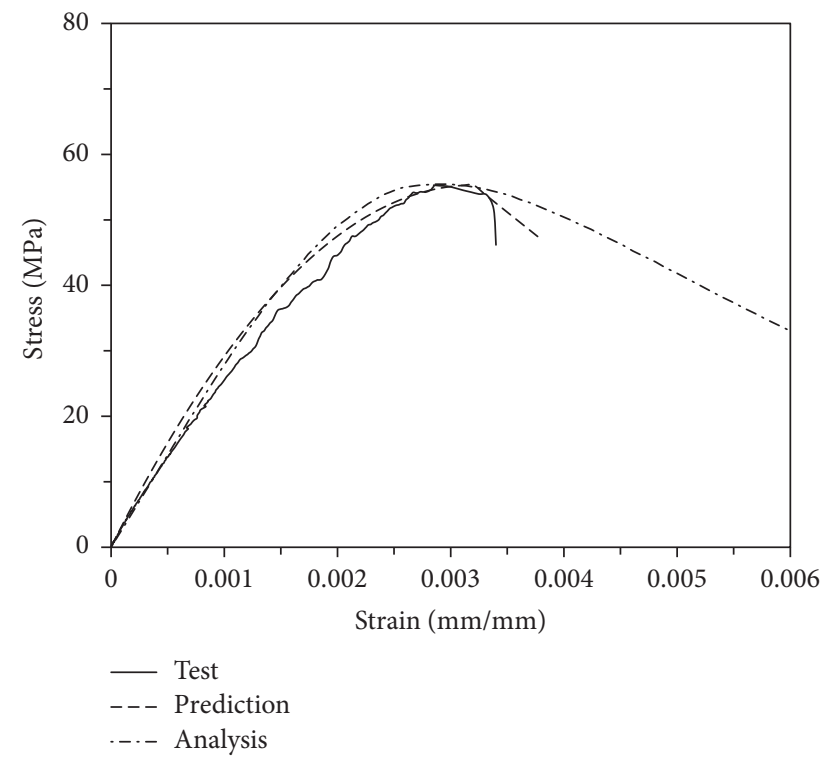

FIGURE 13: Comparison of experimental and predicted stress-strain curves.

4.2. Material Models for Reinforced Concrete. The nonlinear stress-strain relation of a reinforced concrete (RC) in-plane element is formulated based on the concept of space averaging on the control volume. The cracks and reinforcing bars are idealized as being distributed over the entire element. Although the local behavior of the cracked RC is not uniform, in practical terms it can be treated as a continuum having quasi-uniform stress and strain fields in a finite region. The material models aim to describe the overall behavior of a structure rather than a specific local behavior at the element level. In this paper, the term "crack" explicitly refers to the macrocrack perpendicular to the principal tensile direction.

According to the cracking criteria, the analysis models are divided into models before and after the initiation of cracks, as shown in Figure 12. The material model for concrete prior to cracking is based on the elastoplastic fracture model [19] given in Figure 13. The local coordinate systems of reinforcing bars are always assigned with respect to each bar axis, but those of cracked concrete are determined according

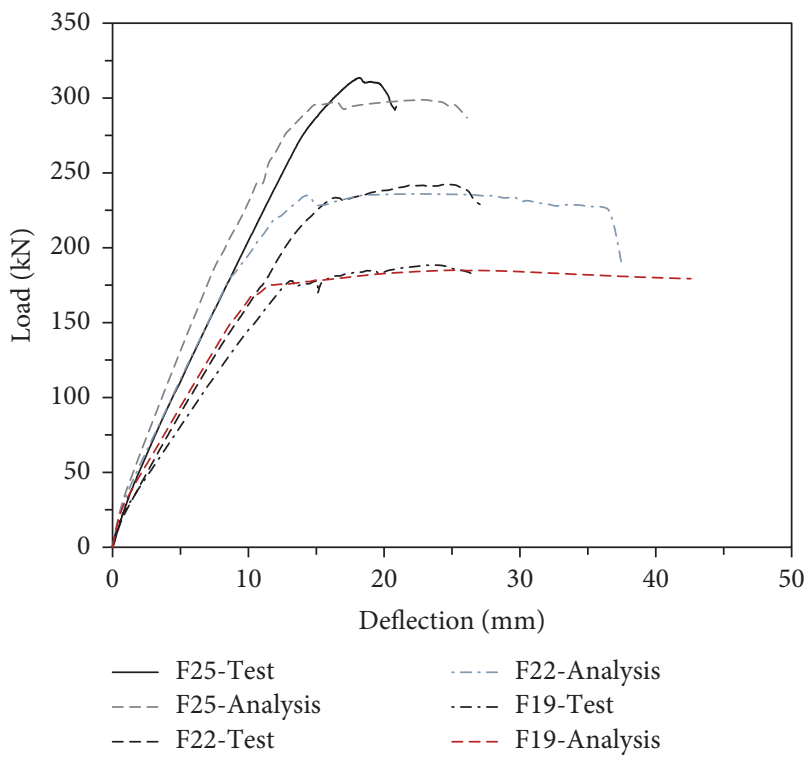

Figure 14: Comparison of experimental and analytical loaddeflection curves for flexure test members.

to the current major crack plane. Once a smeared crack is initiated, it is treated as fixed in a direction, and anisotropy is introduced. As loading step proceeds, the principal direction of the average stress can be changed, and the consequent shear transfer model is involved in the constitutive law.

\section{Comparison of Experimental and Analytical Results}

5.1. Flexure. Figure 14 compares the experimental and analytical load-displacement curves for specimens F25, F22, and F19. The analytical results are in relatively good agreement with the experimental values and indicate the validity of the analytic model. However, for F25 with the largest tensile ratio considered in this study, the test specimens exhibit slight brittle failure compared to the analytical prediction. The initial slope of the experimental curves is on the whole smaller than that of the analytical curves. The different initial slopes 


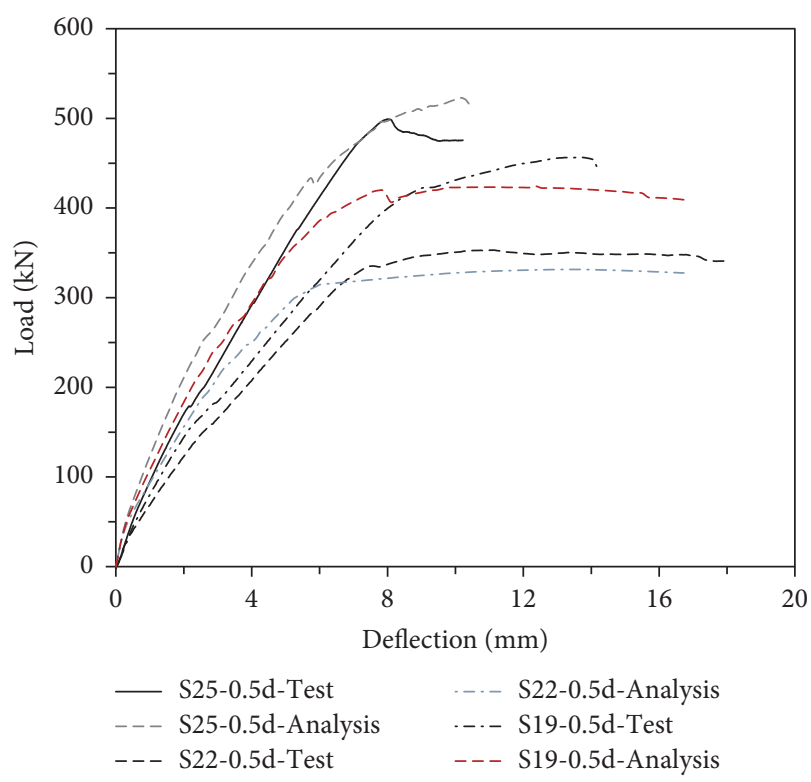

(a) With stirrups

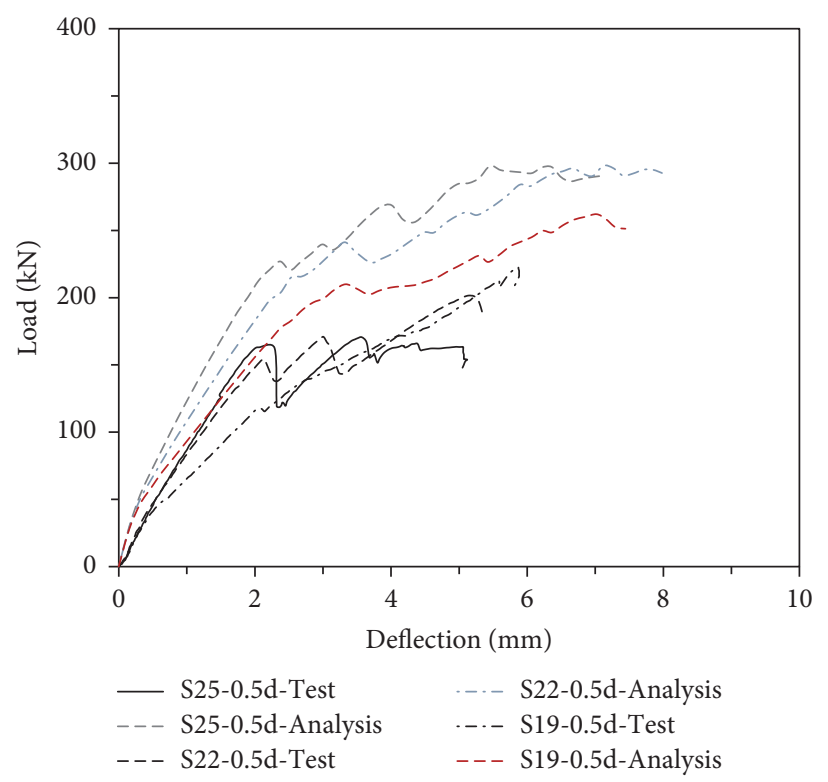

(b) Without stirrup

FIGURE 15: Comparison of experimental and analytical load-displacement curves for shear test members.

of the analytical and experimental results can be attributed partially to the stiffness adopted in the analytical model of the members and some experimental error. Moreover, the early completion of the tests explains the different maximum deflections of the analytical and experimental results. In fact, larger deflection would have been measured in the members that experienced failure through flexure but the tests were interrupted prematurely due to limitations in the capacity of the testing equipment and for the sake of safety.

5.2. Shear. Figure 15 compares the experimental and analytical load-displacement curves of the shear test specimens. The analytical results are in relatively good agreement with the experimental values for the specimens with stirrups. Here also, slight difference in the initial slope occurred as explained above in Section 5.1. Specimen S25-0.5d experienced sudden brittle failure due to the clear occurrence of shear failure. Values near the maximum load could not be measured because of the delay in the acquisition of the data. Besides, the specimens without stirrup showed smaller maximum loads in the test than those of the analysis. However, considering the large experimental errors that are generally observed in the shear test of specimens without stirrup, the results presented here demonstrate to some extent the good execution of the tests performed in this study.

Here also, the early ending of the tests explains the different maximum deflections of the analytical and experimental results. The members without stirrup in Figure 15(b) experienced sudden failure but the tests were interrupted prematurely due to limitations in the capacity of the testing equipment and for the sake of safety. In addition, it is extremely difficult to measure precisely the behavior of the members without stirrup after the ultimate state when the failure test is conducted using an actuator and through displacement control. On the other hand, the similarity of the experimental and analytical maximum deflections observed in Figure 15(a) was achieved because the members suffered shear failure and reached a state close to their ultimate state at the completion of the tests thanks to the presence of stirrups.

\section{Conclusions}

This study evaluated experimentally and analytically the structural behavior of reinforced concrete beams made of AAS concrete. The following conclusions can be drawn from the results.

(1) The elastic modulus and the strain at maximum stress of AAS concrete were slightly smaller than those predicted for normal concrete. This difference could be explained by the reduction in the unit mass of AAS concrete caused by the smaller density of slag compared to cement. Further study shall propose adequate models for the elastic modulus and stressstrain relation of AAS concrete.

(2) The test results of the flexural members showed that the ratio of the ultimate load to the yield load of steel ranged between 1.15 and 1.41 and the load bearing capacity improved with higher tensile steel ratio. The flexural behavior of the reinforced AAS concrete members appeared thus to be very similar to that of the reinforced concrete beam made of normal concrete because the reinforcing bars govern the flexural behavior of the members. A nonlinear flexural analysis model was proposed using the elastic modulus and stress-strain relation of AAS concrete. The analytical results were in good agreement with the 
experimental results and demonstrated the validity of the analytical model.

(3) The experimental shear strength obtained for the members without stirrup was significantly higher than that predicted by the design code, which indicated the conservativeness of the design code. The shear behavior of the reinforced AAS concrete members varied according to the amount of tensile steel.

(4) In view of the finite element analysis results reflecting the nonlinear model of AAS concrete used in previous studies, the flexural and shear behaviors of the AAS concrete specimens were in relatively good agreement with those predicted analytically.

(5) Consequently, the test results show that the flexural and shear behaviors of the reinforced AAS concrete members are very similar to those of the reinforced concrete beam made of normal concrete and render it possible to apply conventional design code for flexure and shear in the design of reinforced AAS concrete members. Further studies are required for the practical use of AAS concrete since this experimental study was limited to specimens with specific dimensions.

\section{Conflicts of Interest}

The authors declare that they have no conflicts of interest.

\section{Acknowledgments}

This research was financially supported by the Korean Ministry of Environment as "Public Technology Program Based on Environmental Policy” (no. 2016000700003). This research was also supported by a grant (Code 11-Technology Innovation-F04) from Construction Technology Innovation Program (CTIP) funded by Ministry of Land and Transport of Korean government.

\section{References}

[1] S.-D. Wang, X.-C. Pu, K. L. Scrivener, and P. L. Pratt, "Alkaliactivated slag cement and concrete: a review of properties and problems," Advances in Cement Research, vol. 7, no. 27, pp. 93$102,1995$.

[2] A. Palomo, M. W. Grutzeck, and M. T. Blanco, "Alkali-activated fly ashes: a cement for the future," Cement and Concrete Research, vol. 29, no. 8, pp. 1323-1329, 1999.

[3] C. Shi, P. V. Krivenko, and D. Roy, Alkali-activated cement and concrete, vol. 376, Taylor \& Francis, Abingdon, UK, 2006.

[4] C. Shi, A. F. Jiménez, and A. Palomo, "New cements for the 21st century: the pursuit of an alternative to Portland cement," Cement and Concrete Research, vol. 41, no. 7, pp. 750-763, 2011.

[5] A. R. Brough and A. Atkinson, "Sodium silicate-based, alkali-activated slag mortars part I. Strength, hydration and microstructure," Cement and Concrete Research, vol. 32, no. 6, pp. 865-879, 2002.

[6] S. Aydin and B. Baradan, "Effect of activator type and content on properties of alkali-activated slag mortars," Composites Part B: Engineering, vol. 57, pp. 166-172, 2014.
[7] S. H. Oh, S. H. Hong, and K. M. Lee, "Autogenous shrinkage properties of high strength alkali activated slag mortar," Journal of the Korean Recycled Construction Resources Institute, vol. 2, no. 1, pp. 60-65, 2014.

[8] F. G. Collins and J. G. Sanjayan, "Workability and mechanical properties of alkali activated slag concrete," Cement and Concrete Research, vol. 29, no. 3, pp. 455-458, 1999.

[9] M. Sofi, J. S. J. van Deventer, P. A. Mendis, and G. C. Lukey, "Engineering properties of inorganic polymer concretes (IPCs)," Cement and Concrete Research, vol. 37, no. 2, pp. 251257, 2007.

[10] C. D. Atiş, C. Bilim, Ö. Çelik, and O. Karahan, "Influence of activator on the strength and drying shrinkage of alkaliactivated slag mortar," Construction and Building Materials, vol. 23, no. 1, pp. 548-555, 2009.

[11] A. A. Melo Neto, M. A. Cincotto, and W. Repette, "Drying and autogenous shrinkage of pastes and mortars with activated slag cement," Cement and Concrete Research, vol. 38, no. 4, pp. 565574, 2008.

[12] F. Puertas, M. Palacios, and T. Vázquez, "Carbonation process of alkali-activated slag mortars," Journal of Materials Science, vol. 41, no. 10, pp. 3071-3082, 2006.

[13] K. Lee and J. Seo, "Evaluation of flexural behavior of reinforced concrete beams using alkali activated slag concrete," Journal of the Korea Concrete Institute, vol. 27, no. 3, pp. 311-317, 2015.

[14] S. Choi, K. Lee, and S. Yoo, "Shear behavior of RC beams using alkali activated slag concrete," Journal of the Korean Recycled Construction Resources Institute, vol. 3, no. 1, pp. 58-63, 2015.

[15] T.-H. Kim, K.-M. Lee, C. Yoon, and H. M. Shin, "Inelastic behavior and ductility capacity of reinforced concrete bridge piers under earthquake. I: Theory and formulation," Journal of Structural Engineering, vol. 129, no. 9, pp. 1199-1207, 2003.

[16] E. Thorenfeldt, A. Tomaszewicz, and J. J. Jensen, "Mechanical properties of high strength concrete and application in design," in Proceedings of the Symposium Utilization of High Strength Concrete, T. Trondheim, Ed., vol. 40, pp. 149-159, Stravanger, Norway, 15-18 June 1987.

[17] S.-W. Shin, S. K. Ghosh, and J. Moreno, "Flexural ductility of ultra-high-strength concrete members," ACI Structural Journal, vol. 86, no. 4, pp. 394-400, 1989.

[18] T.-H. Kim, K.-M. Lee, C. Yoon, and H. M. Shin, "Inelastic behavior and ductility capacity of reinforced concrete bridge piers under earthquake. II: Numerical validation," Journal of Structural Engineering, vol. 129, no. 9, pp. 1208-1219, 2003.

[19] K. Maekawa and H. Okamura, "Deformational behavior and constitutive equation of concrete using the elasto-plastic and fracture model," Journal of the Faculty of Engineering, University of Tokyo, Series B, vol. 37, no. 2, pp. 253-328, 1983. 

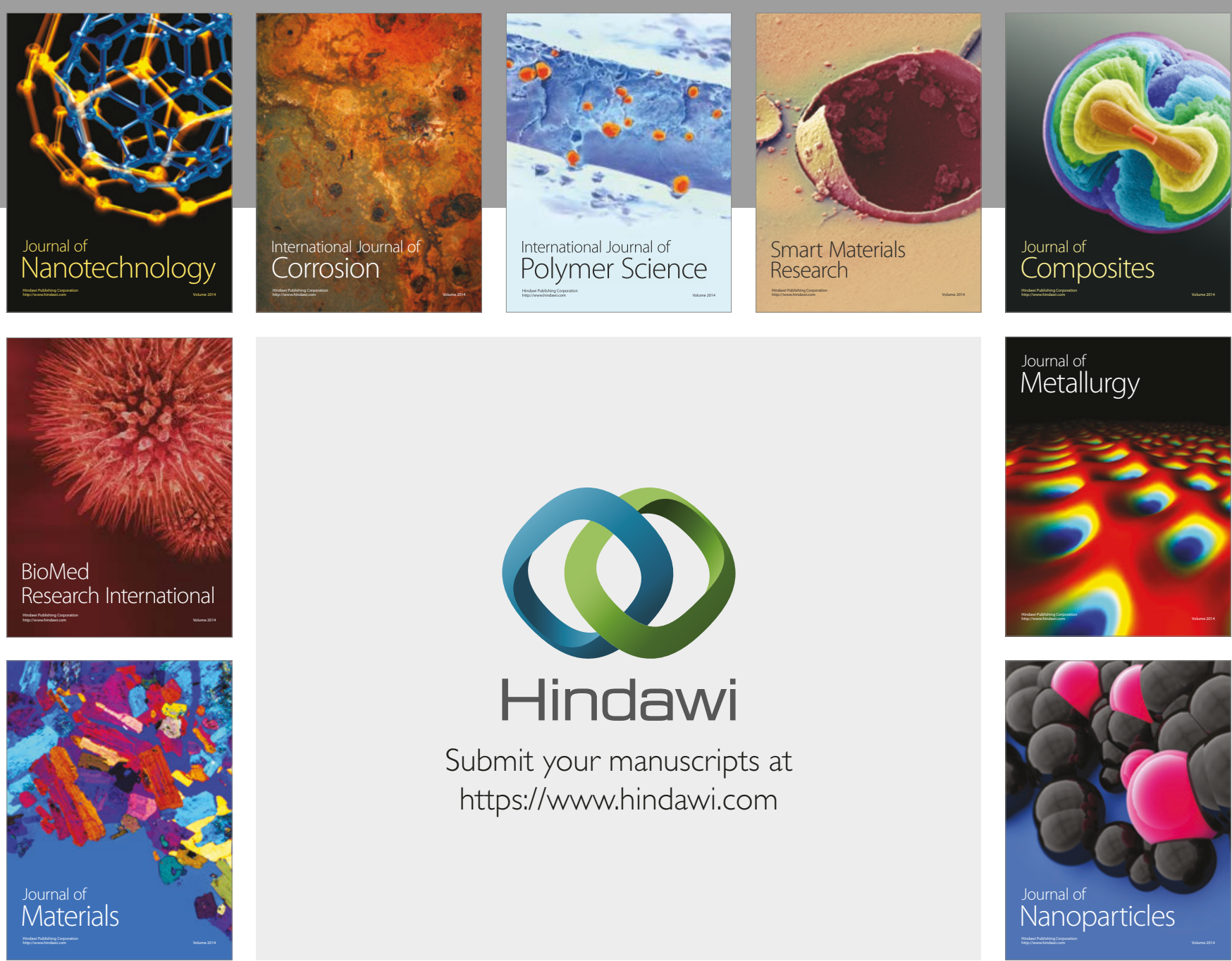

\section{Hindawi}

Submit your manuscripts at

https://www.hindawi.com
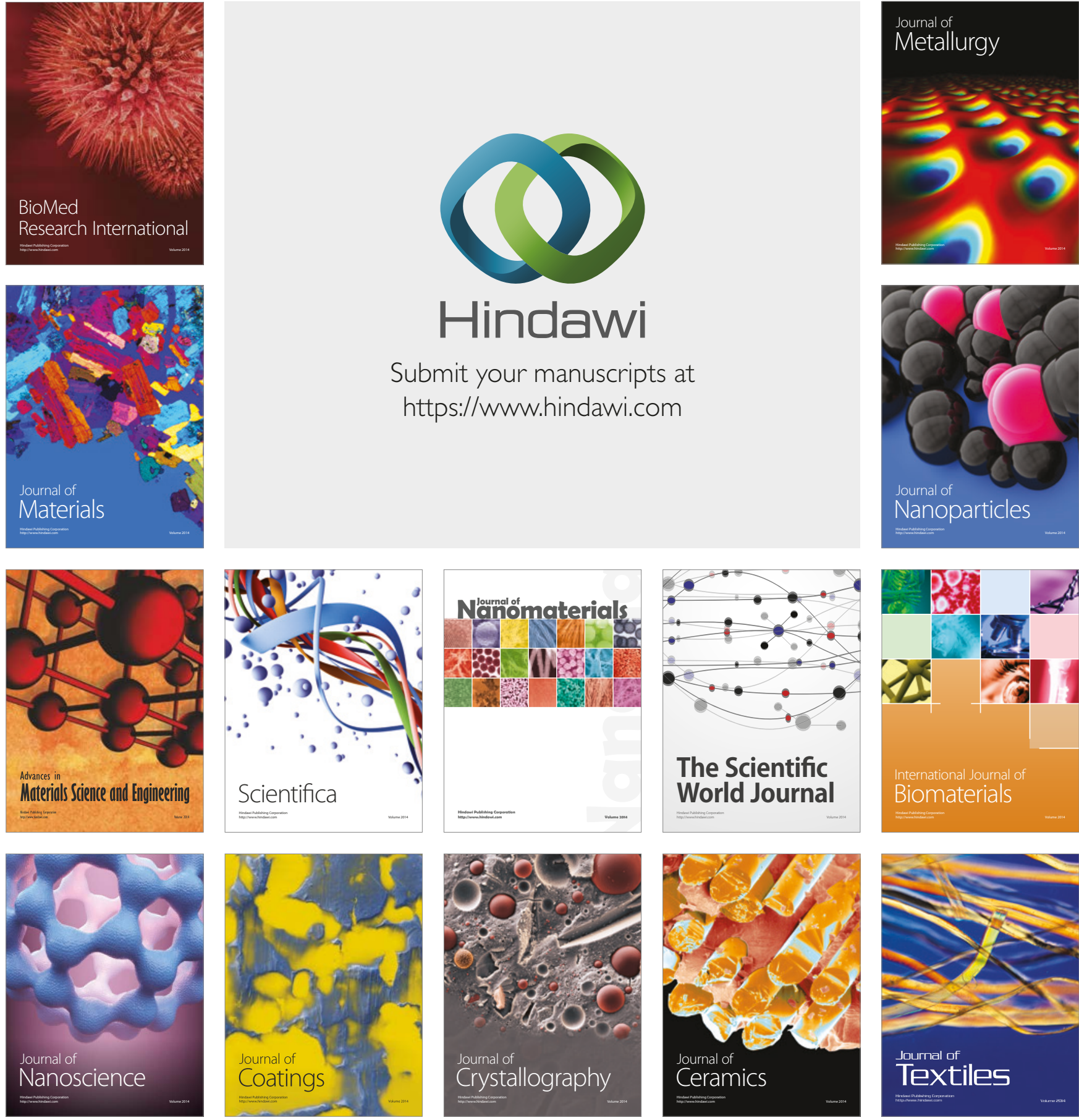

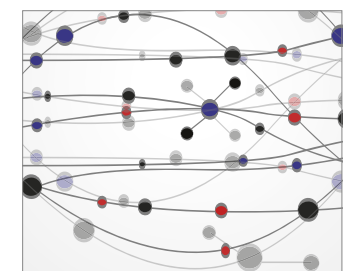

The Scientific World Journal
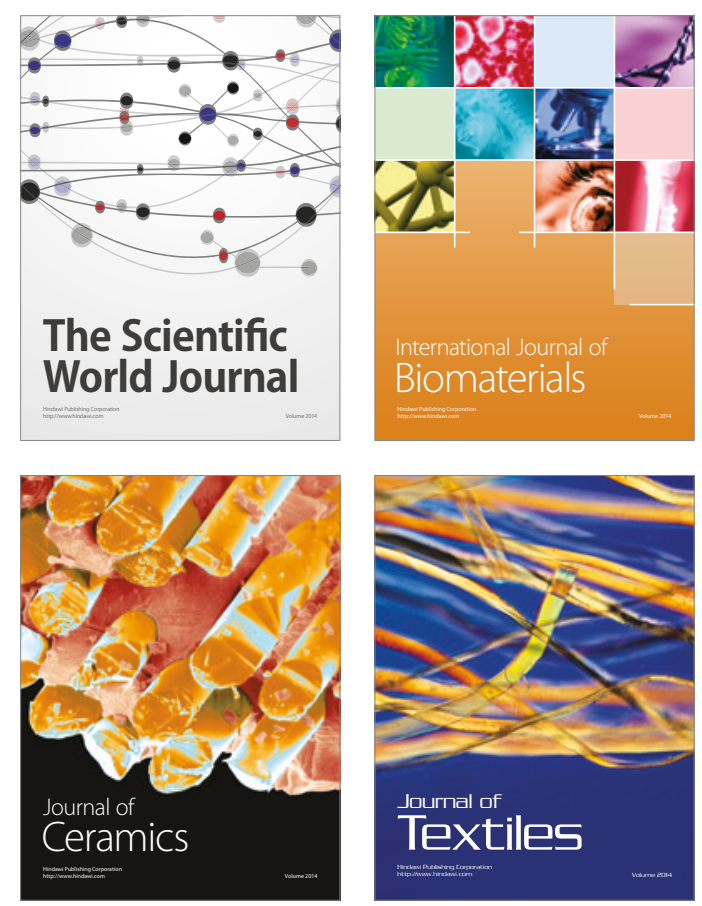